\title{
REFLEXÕES SOBRE AS PRÁTICAS DE EDUCAÇÃO AMBIENTAL EM ESPAÇOS DE EDUCAÇÃO FORMAL, NAOO-FORMAL E INFORMAL
}

\author{
Alini Nunes de Oliveira ${ }^{1}$ \\ Fabiane de Oliveira Domingos ${ }^{2}$ \\ Tatiana Colasante ${ }^{3}$
}

Resumo: A discussão sobre a temática ambiental é essencial, devendo se apresentar permanentemente nos espaços de educação, em todos os níveis e modalidades do processo educativo, ou seja, formal, informal e não-formal. O objetivo deste artigo é analisar em quais modalidades do processo educativo a temática ambiental é contemplada. Esta pesquisa foi realizada a partir de pesquisa bibliográfica e documental para construção do referencial teórico. A partir dos resultados obtidos, conclui-se que é pertinente que os temas relacionados ao meio ambiente possam e devam ser abordados em todos os espaços educacionais, pois abrangem pessoas diferentes, em situações diversas e ampliam a discussão sobre os temas.

Palavras-chave: Educação Ambiental; Educação Formal; Educação Não-formal; Educação Informal.

Abstract: Discussions about the environment are essential and should permanently take place in educational spaces, in all levels and modalities of the educational process, that is, formal, informal and non-formal. This paper aims to analyze in which modalities of the educational process the environmental theme is explored. This study was conducted through bibliographic and documentary research to build the theoretical framework. The results showed that it is relevant that themes related to the environment be addressed in all educational spaces, as they can approach different people, in different situations and broaden the discussion on these themes.

Keywords: Environmental Education; Formal Education; Non-formal Education; Informal Education.

\footnotetext{
1Universidade Federal do Paraná. E-mail: alini nunes@hotmail.com. Link para o Lattes: http://lattes.cnpq.br/8875964393708658

2 Universidade Estadual do Paraná - campus Apucarana. E-mail: fabianedomingos@hotmail.com. Link para o Lattes: http://lattes.cnpq.br/7471596915595753

3 Universidade Federal do Maranhão - campus São Bernardo. E-mail: tatiana.colasante@ufma.br. Link para o Lattes: http://lattes.cnpq.br/2456335844034805
}

Revbea, São Paulo, V. 15, № 7: 09-19, 2020.

revista brasileira educação ambiental 


\section{Introdução}

Com grande frequência, a mídia mostra eventos climáticos que geram grandes desastres, tanto em âmbito local como global, provocados, grande parte das vezes, pela ação humana, tendo como efeitos severos o aumento do efeito estufa, a intensificação do processo de desertificação (causando o empobrecimento dos solos), a poluição dos recursos hídricos (principalmente por agrotóxicos), a poluição do ar, todos esses acarretando no comprometimento da sociobiodiversidade (OLIVEIRA, 2002).

Entende-se que a melhor forma de mudar o cenário atual é por meio da educação. A temática ambiental é essencial e deve ser contemplada permanentemente nos espaços de educação, em todos os níveis e modalidades do processo educativo, ou seja, formal, informal e não-formal.

Sendo assim, a problemática central deste trabalho é definir: é possível abordar a temática ambiental em diferentes espaços de educação, além do formal? A hipótese é de que se pode trabalhar com temas ligados ao meio ambiente nas três principais modalidades do processo educativo, ou seja, formal, informal e não-formal.

O objetivo geral do presente artigo é analisar em quais modalidades do processo educativo a temática ambiental pode ser contemplada. Para tal, temse como objetivos específicos: compreender as diferenças entre as três principais modalidades do processo educativo; investigar de que forma a temática ambiental pode ser abordada em espaços de educação formal; investigar de que forma a temática ambiental pode ser abordada em espaços de educação informal e investigar de que forma a temática ambiental pode ser abordada em espaços de educação não-formal.

A presente pesquisa, de caráter qualitativo, foi realizada a partir de pesquisa bibliográfica (livros, teses, dissertações e artigos científicos publicados em periódicos e anais de eventos) e documental (documentos oficiais disponíveis na internet, relatórios, entre outros) para construção do referencial teórico e caracterização do objeto de estudo.

\section{A emergência das questões ambientais}

Desde o início da década de 1970, existem projetos e programas voltados à Educação Ambiental no Brasil, mas é no final da década de 1980 que se iniciam ações mais concentradas. Segundo Loureiro (2005), principalmente devido à grande mobilização social durante e após a Rio $92 \mathrm{e}$ pela questão ambiental ter tido alcance político, o governo federal (por meio do Ministério da Educação e do Ministério do Meio Ambiente, preponderantemente), instituiu leis e programas importantes, como o Programa Nacional de Educação Ambiental (ProNEA) por meio da Lei Federal n. 9.795/1999, que institui a Política Nacional de Educação Ambiental (PNEA). 
De acordo com Ferraz (2004), há uma grande quantidade de ações diferentes na área ambiental no Brasil, principalmente a partir da Eco-92, que são equivocadamente denominadas de Educação Ambiental, ou seja, grande parte do que é relacionado ao meio ambiente é considerado incorretamente com este termo.

A temática ambiental é bastante relevante e tem se destacado cada vez mais nas escolas, órgãos públicos ambientais, empresas, organizações não-governamentais, entre outros, assim como existem muitas publicações e eventos sobre esta temática, cada um com diferente enfoque conceitual.

Nos últimos anos, as questões ambientais têm sido analisadas de maneira mais contextualizada com as realidades locais, com objetivo emancipatório, numa abordagem holística, passando de um enfoque predominantemente ecológico para algo que incorporasse aspectos sociais, políticos e econômicos e, conforme Reigota (1991, p. 37) salienta,

A problemática ambiental não pode se reduzir só aos aspectos geográficos e biológicos, de um lado, ou só aos aspectos econômicos e sociais, de outro. Nenhum deles, isolado, possibilitará o aprofundamento do conhecimento sobre essa problemática.

A superação dos problemas ambientais exige um despertar do sentimento de pertencimento nas pessoas, de forma que compreendam as relações entre sociedade e natureza. Para isso, deve haver uma profunda conexão entre o ser humano e o local em que vive, aprofundando-se 0 entendimento das questões ambientais (DEPERON, 2004).

Por meio da Educação Ambiental é possível estabelecer práticas e reflexões que consolidem valores voltados à sustentabilidade, à justiça social e à preservação da vida (LOUREIRO, 2005).

Por ser um processo contínuo de reflexão e aprendizagem para exercer a cidadania, ela não é a solução mais rápida para os problemas ambientais, mas é o que possui mais força para capacitar a sociedade a ter uma visão crítica da realidade e uma atuação consciente no espaço onde vive (MEYER, 1991).

Conforme salienta Ferraz (2004), não se deve apenas disponibilizar informações fora do contexto local, sem que as pessoas participem efetivamente das ações e sejam sensibilizadas a se engajar diante das problemáticas do dia a dia.

Não é apenas o espaço escolar que pode contribuir como responsável pela sensibilização da sociedade para as questões ambientais. No Brasil e em diversos países do mundo, existem diversas experiências em que foram trabalhados temas referentes à Educação Ambiental que não aconteceram 
entre os muros da escola, mas sim em espaços mais amplos, como igrejas, parques ecológicos, organizações não-governamentais, associações de moradores, grupos de amigos, escoteiros, propriedades rurais e mesmo em espaços abertos, como o centro da cidade, ou seja, muitos espaços transformam-se em lócus de estudos e reflexões ambientais.

$\mathrm{O}$ ato de educar, independente do público-alvo ou do local em que se encontra, vai muito além da simples reprodução de normas, condutas, comportamentos e atitudes. Refere-se a permitir que as pessoas evoluam, reconheçam o valor que têm, possam exercer a cidadania e reconhecerem-se como pessoas que vivem em comunidade e que dependem dos recursos da natureza para sua sobrevivência.

É fundamental que, nas abordagens da Educação Ambiental, estimulem-se os indivíduos a observarem e expressarem a leitura que fazem do ambiente em que vivem, como um exercício diário. Assim, de forma contextualizada, passam a valorizar a construção do conhecimento a partir de suas vivências individuais e coletivas (MEYER, 1991).

Por meio de leis, decretos e normas nas três esferas governamentais compõem hoje dispositivos que determinam a prática da Educação Ambiental. De acordo com a Lei n. 9.795/1999, que institui a Política de Educação Ambiental no Brasil, seus princípios básicos são:

I - o enfoque humanista, holístico, democrático e participativo;

II - a concepção do meio ambiente em sua totalidade, considerando a interdependência entre o meio natural, o socioeconômico e 0 cultural, sob 0 enfoque da sustentabilidade;

III - o pluralismo de ideias e concepções pedagógicas, na perspectiva da inter, multi e transdisciplinaridade;

IV - a vinculação entre a ética, a educação, o trabalho e as práticas sociais;

$\mathrm{V}$ - a garantia de continuidade e permanência do processo educativo;

$\mathrm{VI}$ - a permanente avaliação crítica do processo educativo;

VII - a abordagem articulada das questões ambientais locais, regionais, nacionais e globais;

VIII - o reconhecimento e o respeito à pluralidade e à diversidade individual e cultural (BRASIL, 1999, s/p).

Percebe-se que a Educação Ambiental deve ser praticada de maneira holística, constituindo-se como componente essencial e permanente da educação como um todo e para todos, devendo estar de forma articulada, em todos os níveis e campos de atuação da educação, ou seja, formal, não-formal e informal. 
O acesso à educação é um direito de todos, garantido pela Constituição Federal, no caso do Brasil, e faz parte da legislação nacional de praticamente todos os países do mundo. Conforme ratifica Gadotti (2005), é um direito necessário que as pessoas devem ter para usufruir de outros direitos constitucionais e fundamentais para a vida. "Negar o acesso a esse direito é negar 0 acesso aos direitos humanos fundamentais. [...] $O$ direito à educação é, sobretudo, o direito de aprender. Não basta estar matriculado numa escola. É preciso conseguir aprender na escola" (GADOTTI, 2005, p. 1).

Existem, basicamente, três modalidades do processo educativo, ou campos de atuação da educação: o formal, o não-formal e o informal.

A educação formal é a modalidade que mais se tem familiaridade, pois é o campo institucionalizado das práticas educativas, regidas inclusive por legislação específica, sendo a única modalidade obrigatória e legalmente legitimada.

Esta modalidade necessita de tempo (regularidade e sequencialidade) e local específicos (basicamente escolas e universidades), além de equipe especializada (professor, coordenador pedagógico, entre outros), planejamento, metodologia e sistematização das atividades a partir de diretrizes regidas por órgãos superiores e deve ser organizada de acordo com a faixa etária e/ou nível de conhecimento do aluno para que, progressivamente, ele alcance níveis superiores e obtenha uma certificação (BRUNO, 2014).

No Brasil, os estados e municípios devem seguir com o planejamento do currículo a partir de diretrizes, vigentes em todo o território nacional, como o PNE (Plano Nacional de Educação), a LDB (Lei de Diretrizes e Bases) e a BNCC (Base Nacional Comum Curricular), organizados pelo MEC (Ministério da Educação). Apesar dos documentos terem diretrizes gerais, cada escola contextualiza de acordo com a sua realidade.

Diferente dos espaços de educação formal, que se pressupõe um espaço com regras e diretrizes educacionais pré-definidas, a educação nãoformal possui ambientes, planejamento e objetivos mais flexíveis.

A não-formal ocorre em ambientes e situações interativos construídos coletivamente, segundo diretrizes de dados grupos, usualmente a participação dos indivíduos é optativa, mas ela também poderá ocorrer por forças de certas circunstâncias da vivência histórica de cada um. Há na educação não-formal uma intencionalidade na ação, no ato de participar, de aprender e de transmitir ou trocar saberes. (GOHN, 2006, s/p).

Segundo Bruno (2014), a educação não-formal não é organizada por faixa etária ou níveis de conhecimento, mas sim, o que é mais relevante serão os temas tratados neste espaço, que são de objetivo comum, podendo atuar 
em aspectos subjetivos do grupo, como os relacionados à cultura, religião, identidade, cidadania, entre outros, priorizando as aprendizagens e saberes coletivos. Conforme salienta Paula (2009), o Terceiro Setor é quem está mais diretamente envolvido com essas práticas e surgiu como alternativa para espaços de novas vivências políticas e sociais. Essa modalidade relaciona-se então diretamente com a Pedagogia Social.

De acordo com Barbosa (2017), a Pedagogia Social é que materializa a educação social e que tem como pilares: a dimensão social do sujeito (ou seja, o educando deve ser considerado como um ser social, inserido em um contexto social cujas relações se dão em diferentes meios); a educação para emancipação (que é seu objetivo maior, ou seja, fazer com que o educando exerça verdadeiramente a cidadania e que se torne independente, socialmente ativo no meio em que vive e ciente de seus direitos e deveres para com a sociedade); a educação social e o assistencialismo (não é a função primordial da educação social relacionar-se com o assistencialismo, mas sim na atuação que busca o empoderamento dos educandos, criando condições para que ele se fortaleça com ideias, conhecimentos, saberes e experiências).

Por último, mas não menos importante, a educação informal, segundo Gohn (2006, s/p), define-se "como aquela que os indivíduos aprendem durante seu processo de socialização - na família, bairro, clube, amigos etc., carregada de valores e culturas próprias, de pertencimento e sentimentos herdados". Mesmo que esses conhecimentos apreendidos não se limitem a um espaço (como no caso da formal e da não-formal), essa modalidade do processo educativo é importante, pois muitas vezes atinge um público que não participaria de atividades relacionadas às outras modalidades e a Educação Ambiental é fundamental para todas as pessoas, de todas as idades, principalmente em se tratando da formação de cidadãos críticos que identifiquem em seu cotidiano possibilidades de ação em prol de atitudes que gerem menos impacto. Contribui também com esta discussão Bruno (2014, p. 14) quando menciona que,

[...] os espaços educativos não estão delimitados e são fortemente marcados por referências de nacionalidade, localidade, idade, gênero, religião, etnia, marcados pela espontaneidade dos ambientes, onde as relações sociais se definem segundo gostos, preferências ou pertencimentos herdados. 
apresentam efeitos educativos" (CAVACO, 2001, p. 49), ou seja, são momentos potencialmente educativos, mesmo que não intencionais ou conscientes por parte dos indivíduos. Por meio da educação informal é possível socializar as pessoas e desenvolver hábitos e atitudes utilizando-se de outros recursos que não apenas o ambiente escolar.

\section{A temática ambiental nos espaços de educação formal, informal e não- formal}

A prática da Educação Ambiental é mais difundida em espaços de educação formal e não-formal. Porém, a educação informal também pode contemplar a temática ambiental.

Em linhas gerais, a Educação Ambiental nos espaços de educação formal é um processo institucionalizado que ocorre nas unidades de ensino, de forma a perpassar por todo o currículo básico dentro dos diferentes componentes curriculares. Já a não-formal é um processo que ocorre fora dos muros da escola, envolvendo a flexibilização de métodos e conteúdos, com público-alvo variável em suas características, podendo ser realizada em diferentes espaços como movimentos sociais, associações e organizações ecológicas, de mulheres, de camponeses, de operários, de jovens, etc., procurando fornecer bases para que a sociedade amplie o conhecimento e possa buscar melhorias por meio de reivindicações políticas, sociais, econômicas e ambientais (REIGOTA, 1991).

$\mathrm{Na}$ educação formal, a temática ambiental conquistou mais espaço com os Parâmetros Curriculares Nacionais (PCNs) a partir de 1996. Até dezembro deste ano, o ensino fundamental estava estruturado pela Lei Federal n. 5.692, de 11 de agosto de 1971. A Lei de Diretrizes e Bases da Educação Nacional - LDB (Lei Federal n. 9.394), aprovada em 20 de dezembro de 1996 (e com ela os PCNs) veio então para atualizar as intencionalidades do governo federal em relação às políticas educacionais como um todo. No que tange à temática ambiental, a proposta era de que o meio ambiente fosse tratado de maneira transversal em todas as disciplinas. Foi criado, na época, dentre os dez volumes, um específico intitulado "Meio ambiente e saúde" (BRASIL, 1997).

As Diretrizes Curriculares Nacionais da Educação Básica (DCNs), em seu documento mais atual de 2013, preconiza a existência de uma base comum curricular que garanta que todos os alunos tenham os mesmos conhecimentos e desenvolvam as mesmas competências e habilidades em todo o país. Para isso, foi criada a Base Nacional Comum Curricular (BNCC), documento de caráter normativo que define as aprendizagens essenciais da educação infantil e ensino fundamental, já aprovada e homologada em dezembro de 2017, e ainda em trâmites para aprovação a do ensino médio. A BNCC define as competências gerais, competências específicas de área e competências específicas de cada componente curricular, além das habilidades de cada etapa e também os temas contemporâneos que devem ser 
contemplados no contexto dos componentes curriculares. É dessa forma que a temática ambiental novamente é reforçada nos ambientes escolares, a partir da Lei no 9.795, de 27 de abril de 1999, que institui a Política Nacional de Educação Ambiental (BRASIL, 2017).

Sendo assim, por lei, as escolas devem integrar em seus currículos as discussões acerca do meio ambiente de uma maneira holística e transversal, perpassando por todos os componentes curriculares (Língua Portuguesa, Matemática, História, Geografia, Ciências, etc.) de modo que os alunos compreendam a importância da conservação e preservação dos recursos naturais para a manutenção da vida no planeta.

Quando se trata da educação não-formal, a possibilidade de se trabalhar com as questões ambientais também é tão ampla quanto na educação formal. Conforme Seção III, art. 13, da Lei no 9795, de 27 de abril de 1999, "Entende-se por Educação Ambiental não-formal as ações e práticas educativas voltadas à sensibilização da coletividade sobre as questões ambientais e à sua organização e participação na defesa da qualidade do meio ambiente". De acordo com esse mesmo documento, o poder público incentiva a participação das escolas, universidades e organizações não-governamentais (ONGs), em parceria com empresas públicas e privadas, a organizarem e executarem programas voltados a práticas de Educação Ambiental, que abranjam também a sensibilização da sociedade para a relevância das unidades de conservação (UCs), assim como a sensibilização ambiental de agricultores, populações tradicionais, ecoturistas, entre outros.

As práticas de Educação Ambiental em espaços não-formais, em sua maioria, eram organizadas por ONGs, movimentos sociais e órgãos públicos ligados diretamente à área ambiental. Porém, conforme ratifica Reis, Semêdo e Gomes (2012) existem poucos recursos financeiros disponíveis para trabalhos no âmbito da educação não-formal. O que ocorre é que nas unidades de conservação (tanto federais, quanto estaduais e municipais) algumas atividades ainda ocorrem com parcerias e alguns poucos patrocínios. Hoje outras instâncias estão envolvidas nesses trabalhos de Educação Ambiental, como o setor privado, principalmente implementando programas voltados à responsabilidade socioambiental.

Assim como nas escolas, os trabalhos de Educação Ambiental são bastante desenvolvidos em outros espaços que abrangem a educação nãoformal, como unidades de conservação, associações e outros espaços ligados diretamente e indiretamente aos diversos temas relacionados ao meio ambiente.

Já na educação informal, a temática ambiental é menos discutida, mas tem uma importância fundamental, pois é nela que se encontra a chance de crescimento e renovação da Educação Ambiental. De acordo com Layrargues (2012, p. 409), "a mídia tem se constituído numa ferramenta bastante eficiente para reproduzir seus valores no tecido social". 
A Educação Ambiental no âmbito informal, segundo Coimbra e Cunha (2005, p. 2) "[...] é aquela realizada fora dos recintos escolares, podendo ocorrer por meio de campanhas populares que visem a formação de atos e atitudes que possibilitem a preservação dos recursos naturais e a correção de processos degenerativos da qualidade de vida". A todo momento, tanto na televisão, quanto na internet, principalmente em redes sociais, há o compartilhamento de informações a respeito de temáticas relativas ao meio ambiente e, quando utilizado corretamente, é uma ferramenta importante de sensibilização ambiental.

\section{Conclusões}

É com urgência que se devem consolidar as discussões e práticas que envolvam a temática ambiental em espaços educacionais formais, não-formais e informais, já que há possibilidade real de escassez de recursos naturais que garantam a sobrevivência humana. A sociedade tem caminhado, mesmo que a passos lentos, para reflexões que visem a outro modelo de desenvolvimento numa ótica menos degradante.

Hoje, por lei, as escolas devem integrar em seus currículos as discussões acerca do meio ambiente de uma maneira holística e transversal, perpassando por todos os componentes curriculares.

A partir das leituras realizadas por meio da pesquisa bibliográfica e documental, percebeu-se que não somente dentro dos currículos escolares é que se aborda a temática ambiental, mas também em outras modalidades educacionais, como os espaços de educação não-formal e informal.

A hipótese do trabalho respondeu a problemática inicial, pois é possível e necessário que sejam abordados os temas referentes ao meio ambiente em outros espaços, como movimentos sociais, unidades de conservação, igrejas, associações e também nos espaços midiáticos, que possuem vital importância tanto quanto a educação formal, já que abrange um número maior de pessoas, com objetivo de melhorar cada dia mais a convivência do ser humano com o meio em que vive, pensando então nas gerações futuras.

\section{Referências}

BARBOSA, R. C. M. Fundamentos da Pedagogia Social. Valinhos: 2017.

BRASIL. Ministério da Educação. Secretaria de Educação Básica. Base nacional comum curricular: educação é a base. Brasília: MEC/SEB, 2017. Disponível em: $<$ http://basenacionalcomum.mec.gov.br/images/BNCC El EF 110518 versaofi nal site.pdf>. Acesso em: 2 de outubro de 2018. 
BRASIL. Lei $\mathbf{n}^{\circ}$ 9795, de 27 de abril de 1999. Dispõe sobre a Educação Ambiental, institui a Política Nacional de Educação Ambiental e dá outras providências. Disponível em: <www.planalto.gov.br/ccivil 03/LEIS/L9795.htm>. Acesso em: 2 de novembro de 2018.

BRASIL. Ministério da Educação. Secretaria de Educação Fundamental. Parâmetros Curriculares Nacionais: introdução aos parâmetros curriculares nacionais. Brasília: MEC/SEF, 1997. Disponível em: $<$ http://portal.mec.gov.br/seb/arquivos/pdf/livro01.pdf>. Acesso em: 5 de outubro de 2018.

BRUNO, A. Educação formal, não formal e informal: da trilogia aos cruzamentos, dos hibridismos a outros contributos. Mediações, v. 2, n. 2, p. 10-25, 2014.

CAVACO, C. J. D. Processo de formação de adultos não escolarizados - a educação informal e a formação experiencial. Dissertação (Mestrado em Ciência da Educação). Universidade de Lisboa, Portugal, 2001. Disponível em: $<$ https://repositorio.ul.pt/handle/10451/28081>. Acesso em: 20 de novembro de 2018.

COIMBRA, F. G.; CUNHA, A. M. O. A Educação Ambiental não formal em unidades de conservação: a experiência do Parque Municipal Vitório Siquierolli. In: ENCONTRO NACIONAL DE PESQUISA EM EDUCAÇÃO EM CIÊNCIAS, 5., Bauru, 2005. Anais... Associação Brasileira de Pesquisa em Educação em Ciências, Bauru, $2005 . \quad$ Disponível em: $<$ www.nutes.ufri.br/abrapec/venpec/conteudo/artigos/1/pdf/p483.pdf>. Acesso em: 3 de outubro de 2018.

DEPERON, M. L. S. Educação Ambiental, ética e cidadania planetária. In: HAMMES, V. S. Construção da proposta pedagógica. São Paulo: Embrapa/Globo, 2004. p. 42-45.

FERRAZ, J. M. G. Educação Ambiental e mudança de valores. In: HAMMES, V. S. Proposta metodológica de macroeducação. São Paulo: Embrapa/Globo, 2004. p. 150-152.

GADOTTI, M. A questão da educação formal/não-formal. Institut International des Doits de L'enfant (IDE). Droit à l'éducation: solution à tous les problèmes ou problème sans solution? Sion, 2005. Disponível em: <http://bit.do/eSJtP>. Acesso em: 2 de novembro de 2018.

GOHN, M. da G. Educação Não-Formal na pedagogia social. In: CONGRESSO INTERNACIONAL DE PEDAGOGIA SOCIAL, 1., São Paulo, 2006. Anais... Faculdade de Educação, Universidade de São Paulo, São Paulo, 2006. Disponível em: $<$ www.proceedings.scielo.br/scielo.php?pid=MSC0000000092006000100034\&s cript=sci arttext $>$. Acesso em: 3 de outubro de 2018. 
LAYRARGUES, P. P. Para onde vai a Educação Ambiental? O cenário políticoideológico da Educação Ambiental brasileira e os desafios de uma agenda política crítica contra-hegemônica. Revista Contemporânea de Educação, v. 7, n. 14, p. 388-411, ago./dez. 2012.

LOUREIRO, C. F. B. Abordagens metodológicas em Educação Ambiental. In: ARAÚJO, M. L.; SILVA, M. L. (Orgs.). Múltiplas falas, saberes e olhares: os Encontros de Educação Ambiental no Estado do Pará. Belém: SECTAM, 2005. p. $85-103$.

MEYER, M. A. de A. Educação Ambiental: uma proposta pedagógica. Em Aberto, Brasília, v. 10, n. 49, p. 41-46, jan./mar. 1991.

OLIVEIRA, E. M. de. A crise ambiental e suas implicações na produção do conhecimento. In: QUINTAS, J. S. (Org.). Pensando e praticando a Educação Ambiental na gestão do meio ambiente. Brasília: IBAMA, 2002. p. 75-90.

PAULA, E. M. A. T. Educação Popular, Educação Não Formal e Pedagogia Social: Análise de conceitos e implicações para a Educação Brasileira e Formação de professores. In: CONGRESSO NACIONAL DE EDUCAÇÃO, 9., 2006. Anais... Pontifícia Universidade Católica, Curitiba, 2006. Disponível em: $<$ https://educere.bruc.com.br/arquivo/pdf2009/2103 1034.pdf>. Acesso em: 3 de outubro de 2018.

REIGOTA, M. Fundamentos teóricos para a realização da Educação Ambiental popular. Em Aberto, Brasília, v. 10, n. 49, p. 35-40, jan./mar. 1991.

REIS, L. C. L. dos; SÊMEDO, L. T. de A. S.; GOMES, R. C. Conscientização Ambiental: da Educação Formal a Não Formal. Revista Fluminense de Extensão Universitária, Vassouras, v. 2, n. 1, p. 47-60, jan./jun. 2012. 